\title{
OS CONFLITOS E VALORES NA JUVENTUDE: TRANSIÇÃO PARA A MATURIDADE
}

\author{
The Conflicts and Values in Youth: Transition to Maturity \\ Los Conflictos y los Valores en la Juventud: Transición a la Madurez
}

Simeia Rodrigues CAMPOS

TOMMY AKIRA Goto

\begin{abstract}
Resumo: O trabalho aborda os principais pontos de uma investigação qualitativa, com a pesquisa bibliográfica relativa ao entendimento do jovem brasileiro em seus conflitos relacionais, na transição para a maturidade, e como os valores existenciais se consolidam nesse período. Ao considerar o jovem na interdependência com seu contexto social, a partir da visão da Psicologia Compreensiva de Eduard Spranger, objetivou-se entender esse indivíduo em sua construção social, composta de valores das múltiplas esferas que abarcam os sentidos da vida; e verificar como tais identidades constituídas pela sociedade atual têm potencial para alterar a realidade concreta dos jovens. O estudo favoreceu a percepção de inúmeras especificidades de tais sujeitos; com isso, fornece elementos importantes para conceber a juventude em sua multiplicidade (juventudes), bem como uma nova ênfase das políticas públicas e o redesenho do espaço-tempo do jovem. Concluiu-se que a juventude se constitui enquanto sujeito social de forma ambígua, revelando aceitação e negação das imposições da fase adulta - isso inclui a reinterpretação de valores existenciais e a própria concepção de mundo.
\end{abstract}

Palavras-chave: Crise Generativa; Identidade; Juventude; Psicologia.

\begin{abstract}
This work approaches the main points of a qualitative study, with a bibliographic research referred to understanding of young Brazilian in his/her relational conflicts in the transition to maturity and how the existential values are consolidated in this periodo. Considering the young in the interdependence with his/her social context, from the vision of Comprehensive Psychology of Eduard Spranger, it aimed to understand this individual in his/her social construction, composed by values from multiple spheres that embrace the senses of life; and verify how such identities constituted by present society have a potential to change the concrete reality of young people. The study developed a perception of numerous specificities of these subjects; thus, it provides important elements to conceive the youth in its multiplicity (youths), as well as a new focus of public policy and the redesign of young people's space-time. In conclusion, youth is constituted as a social subject in an ambiguous way, revealing acceptance and denial of adulthood impositions - it includes the reinterpretation of existential values and an own world perception.
\end{abstract}

Keywords: Generative Crisis; Identity; Youth; Psychology.

Resumen: La obra cubre los puntos principales de una investigación cualitativa con la literatura sobre la comprensión de los jóvenes de Brasil en sus conflictos relacionales, la transición a la madurez, y como los valores existenciales se consolidan en este periodo. Al considerar a los jóvenes interdependencia con su contexto social, desde la perspectiva de la Psicología Integral Eduard Spranger, se tuvo como objetivo comprender a esta persona en su construcción social, que consta de varios valores esferas que abarcan los significados de la vida; y ver cómo tales identidades constituidas por la sociedad actual tiene el potencial de cambiar la realidad concreta de los jóvenes. El estudio favoreció la percepción de muchas características especiales de tales materias; proporciona elementos importantes para el diseño de los jóvenes en su multiplicidad (jóvenes) y un nuevo énfasis de la política pública y el rediseño del espacio-tiempo del joven. Se concluyó que la juventud se constituye como sujeto social ambigua, revelando la aceptación y el rechazo de la edad adulta cargos - esto incluye la reinterpretación de los valores existenciales y la propia concepción del mundo.

Palabras-clave: Crisis generativo; la identidad; la juventud; Psicología.

\section{Introdução}

A juventude configura um fenômeno atual e significativo para a sociedade, que está permeado pelos valores e condutas não só entre seus grupos, mas também determinando conceitos culturais para os sucessores no contexto social, deixando-lhes um legado de transformações e novas concepções. Assim, nesse artigo tem a intenção de, a partir da Psicologia Compreensiva de Eduard Spranger, entender a "juventude”, composta de valores das múltiplas esferas que abarcam os sentidos da vida; ainda, em explicitar como a identidade, constituída pela sociedade atual, tem potencial para alterar a realidade concreta dos jovens.

Abordar os conflitos vivenciados pelos jovens na sua transição para maturidade requer a contextualização do espaço e do tempo desses indivíduos. Por exemplo, segundo Waiselfisz (2014), no Brasil existem mais de 52,2 milhões de jovens, com faixa etária entre 15 e 29 anos, 
em que muitos ainda vivem situações de desigualdade e são vítimas de problemas socioeconômicos. Nesse sentido, há anos vêm se tentando estabelecer e desenvolver cada vez mais políticas públicas para a juventude, destinadas a intervir naqueles que compõem esse grupo social.

Apesar de as mudanças serem lentas, já foram realizadas várias iniciativas em relação à realidade dos jovens em nosso país. Consideramos que o Brasil convive com transformações expressivas nas políticas para juventude como a criação da Política Nacional de Juventude pela Secretaria Nacional de Juventude da Secretaria-Geral da Presidência da República em 2004 que tem contribuído na construção de um novo paradigma em torno da questão. Com isso, orientações que integrem tais caminhos poderão cooperar para novas percepções em torno dos direitos da juventude. Mesmo assim ressaltamos que grande parte dessa juventude ainda não sabe o que significam os direitos de um jovem. Embora os avanços tenham sido relevantes na problemática da juventude, sabemos que a maioria desses indivíduos ainda continua sem acesso a direitos básicos, como saúde, educação, trabalho e cultura e segurança (Amorim, 2011).

Vale considerar também o conjunto de questões sociais do nosso país que são amplificadas quando o recorte diz respeito ao público jovem. Necessitamos trabalhar e enxergar como o Estado brasileiro irá resolver essas demandas ou o que falta para fazer isso. A segurança, por exemplo, é um dos aspectos a serem analisados como prioridade, pois é inaceitável a quantidade de mortes que ocorrem nesse público, principalmente entre os pobres e negros da periferia, como se estivéssemos em guerra. Assim, Waiselfisz (2014) ainda existe uma evolução histórica da mortalidade violenta no Brasil que, segundo os registros do Sistema de Informações de Mortalidade, entre os anos 1980 e 2012, morreram no país: 1.202 .245 pessoas vítimas de homicídio; 1.041 .335 vítimas de acidentes de transporte; 216.211 suicidaram-se., obtendo-se por fim, uma totalidade de 2.459.791 vítimas.

De fato, a violência tem marcado drasticamente a experiência dessa geração. Ao constatarmos que esse problema tem idade, cor/raça espaço e tempo, destacamos que em 2012, por exemplo, as vítimas por homicídios chegaram a 30.072 jovens, isto é, $53 \%$ do total de homicídios ocorridos no país (Secretaria Nacional de Juventude, 2014). Recentemente, apenas, a demanda juvenil entrou na pauta das políticas públicas. Podemos dizer que essas ações adquiriram força a partir de 2005, com a execução da Política Nacional de Juventude (PNJ), o que nos proporcionou quase uma década de avanços significativos em termos de políticas: aumento no número de jovens que ingressam no ensino superior; retirada de milhões deles das condições de miséria e pobreza; e possibilidade de mecanismos de participação social como forma de engajá-los na realidade de próprio ambiente. Ainda constatamos que a juventude foi incluída na Constituição Federal por meio da Emenda n. 65/2010 e, assim, avançamos na criação de órgãos e conselhos específicos nos estados e municípios, referentes à manutenção dos benefícios destinados a esse grupo (Amorim, 2011).

Outro ponto é a formalização de empregos que ajudem na qualidade e estabilidade do trabalho remunerado entre os jovens, pois ainda são grandes e graves os problemas para esse segmento. Apesar das conquistas políticas e sociais realizadas por nossos jovens e apoiadores, o Brasil enfrenta sérias dificuldades sociais pertinentes ao tema, uma vez que a taxa de desemprego entre eles cada vez mais é elevada, com uma taxa de desemprego que chega a 28,8\% entre a faixa etária de 18 a 24 anos (IPEA, 2017). Nesse sentido, consideramos desafios para agenda governamental: o investimento a novas oportunidades de emprego e a segurança de trabalho decente para os jovens; o compromisso com a educação de qualidade, a saúde integral, o acesso à cultura, ao esporte e ao lazer, além do tempo livre; e o direito à participação na sociedade. (Secretaria Nacional de Juventude, 2014).

Em uma tentativa governamental de intervir nas situações descritas como desafios foi criada a Secretaria Nacional de Juventude (SNJ), efetivada pelo Decreto-Lei n. 11.129/2005, junto ao Programa Nacional de Inclusão de Jovens (ProJovem) e ao Conselho Nacional de Juventude (Conjuve). Nesse entremeio, consideramos o jovem como objeto de estudo percebido na relação de interdependência no contexto social, em que as mudanças ocorrem dialeticamente por meio de articulações e dinâmicas sociais. Visamos entender como ele é uma construção social composta dos valores das múltiplas esferas que abrangem os sentidos da vida, e observaremos como as identidades sociais têm potencial para alterar a realidade concreta do ser humano e, com isso, transformar o estilo de vida.

\section{Método}

Esperamos, mediante um olhar mais sistemático e proporcionado pela pesquisa acadêmica, conhecer os aspectos que perpassam a vida do jovem brasileiro na atualidade e as condições de enfrentamentos na sua realidade. Sabemos que a estratégia de investigação aponta as opções teóricas básicas e, assim, exibe as implicações do caminho a ser percorrido para a apreensão da realidade elegida e sua relação com o sujeito (Minayo, 1994). Desse modo, vemos a metodologia como um meio de comunicação que nos oferece o método indicado como luz na condução da pesquisa (Lima \& Mioto, 2007). Rosa e Arnoldi (2006) mencionam a pesquisa como um trabalho de busca apropriada para proporcionar e produzir conhecimento novo de alguma área ou fenômeno, sistematizando-o em relação ao saber já conhecido.

Para a condução do nosso estudo exploratório utilizamos uma investigação qualitativa e bibliográfica do fenômeno juventude, pois traz maior proximidade com o assunto, permitindo alcançar os objetivos expostos. Nes- 
se sentido, a pesquisa envolveu um diálogo entre autores clássicos como Eduard Spranger (1970; 1976), Delfim Santos (1943) e Donald W. Winnicott (1987), que nos instruem sobre a constituição e a formação psicológica e social dos jovens; e pensadores contemporâneos, a exemplo de Zygmunt Bauman (2005), Peter Berger e Thomas Luckmann (2004), Ceneide Cerveny e Cristina Berthoud (2001), Stuart Hall (2006), Regina Herzog e Ricardo Salztrager (2003), Maria Bernadete Oliveira (2006), Luiz Carlos Osório (1996), Cynthia Andersen Sarti (2004), Paula Sibilia (2008) que contextualizam os jovens na realidade atual.

No que tange aos aspectos político-econômicos e sociais dos jovens, fundamentamos nosso estudo alguns teóricos como Ricardo Amorim (2011), Franciele Carvalho, Leonardo Rodrigues, Josemar Rosa e Laila Santana (2011), Roselani Sodré Silva e Vini Rabassa Silva (2011). A exploração do assunto e dos conteúdos constituintes das personalidades desses sujeitos será feita a partir de buscas e leituras de livros e artigos científicos destinados à pesquisa acadêmica.

A pesquisa bibliográfica que desenvolvemos aqui consistiu no exame da literatura como levantamento e análise de informações de produções sobre o tema, como também uma investigação qualitativa focada nas obras de Eduard Spranger (1970, 1976). Também consultamos artigos nas bases de dados dos veículos de informações acadêmicas - BVS, Mendeley, Redalyc e SciELO -, utilizando como descritores os termos "crise generativa", "identidade", "juventude" e "psicologia” que puderam atualizar o nosso contexto de análise.

O caminho percorrido para a elaboração da pesquisa foi assim realizado: primeiro, houve uma leitura exploratória, buscando informações a respeito do tema e em consonância com nossos objetivos de estudo. Nesse caso selecionamos alguns artigos relevantes e, a partir de uma leitura seletiva, escolhemos quais materiais seriam aproveitados na pesquisa, elegendo as informações pertinentes com os alvos. Em seguida, lemos detalhadamente o material encontrado, procurando respostas à nossa problematização e, posteriormente, catalogamos os dados e as opiniões dos autores.

Depois disso organizamos este texto a partir da análise dos elementos e conforme a proposta pretendida, configurando assim o referencial teórico. A discussão a respeito dos instrumentos e a análise do tema ocorrem juntas e imbricadas, tendo em vista que o conhecimento é sempre parcial, por ser produzido a partir de um recorte. Assim, cada informação adquirida é uma versão com interpretação parcial.

\section{A psicologia compreensiva e a questão da juventude}

O principal aporte teórico escolhido nesse estudo, como meio para entender o desenvolvimento psicológico do jovem, advém da denominada "Psicologia Compreensi- va" de Eduard Spranger, filósofo e psicólogo alemão que nasceu em Berlim, em 1882, e morreu em Tübingen, em 1963. Foi discípulo de Wilhelm Dilthey, filósofo e historiador alemão; se manteve ativo como livre docente na Universidade de Berlim e, posteriormente, na Universidade de Tübingen, que regeu a cátedra de Filosofia até seu falecimento, aos 81 anos.

Além dos caminhos monográficos percorridos nos primeiros estudos, em relação às obras de Humboldt e Goethe, Eduard Spranger foi o autor, entre outros títulos, de "Formas de Vida" (1914), texto em que descreveu seis tipos ideais na personalidade em conexão com os valores estético, teórico, social, econômico, político e religioso. Outros destaques de sua produção se referem a "Cultura e Educação" (1919), "Comunidade Nacional, Estado, Educação” (1932), “O Educador Nato” (1958) e "Psicologia da Juventude" (1970).

Em sua carreira intelectual, Spranger praticou e defendeu a denominada "Psicologia Compreensiva", rotulada à época também como Psicologia Estrutural. Para ele, o entendimento sobre a totalidade da vida psíquica evidencia as experiências mais importantes correspondentes aos atos do sujeito, e isso se torna o centro da investigação. Para o referido estudioso, as formações psíquicas são influenciadas pelo espírito e, consequentemente, pela cultura; logo, podem ser reduzidas a esquemas ou estruturas básicas (Ferreira, 1984).

Em se tratando dos estudos da personalidade como um interesse integrativo perante a dispersão e fragmentação das pesquisas em processos fundamentais, podemos discorrer que alguns autores restauram a importância da experiência consciente para a Psicologia. Essa tendência é representada pelos trabalhos de Spranger que, a partir de diferentes pontos de vistas, ressaltam ideias convergentes - a maioria deles defende uma Psicologia Compreensiva, apropriada para analisar o sujeito em sua particularidade e totalidade, e a reprodução dos conceitos por ela instituídos permite nova direção na psicologia. Nesse sentido, podemos ver os esforços dos compreensivistas na retomada das questões vivenciais que propiciaram o lugar da consciência na pesquisa e na prática psicológica (Gomes, Holanda, \& Gauer, 2004).

Segundo Santos (1943), no campo da observação, os eventos acontecem em contraposição a outras esferas do saber mais objetivo. Lembramos a importância da Psicologia, que leva em conta a compreensão do homem enquanto homem e, sob o signo da antropologia e da caracterologia, considera o conhecimento concreto do homem que lhe interessa. De tal modo, o conhecimento do homem, do seu temperamento e caráter, é alcançado quando a Psicologia simplesmente não se restringe à deliberação dos tempos de reação, da gradação sensorial ou das hipóteses funcionais do córtex. Afinal, a Psicologia é um instrumento de elucidação da vida anímica do homem, ou seja, mais do que qualquer outra ciência, ela não tem a intenção em si, e sim o homem como objeto final. 
Nota-se que há tentativas importantes para compreender o que deve ser a Psicologia. Alguns dizem que existe apenas uma; entretanto, juntamente com a Psicologia Explicativa estão as Psicologias: Compreensiva e Hermenêutica. Além da Psicologia Indutiva e Generalizadora há as Psicologias Interpretativa, Estrutural e Totalitária (Santos, 1943).

Na Psicologia Compreensiva, o psíquico tem uma estrutura particular e, para o seu conhecimento, exigem-se princípios mais adequados. As noções de estrutura, forma e totalidade foram utilizadas como ferramentas úteis para o conhecimento do psiquismo, e, apesar de sua aplicação como metodologia ser algo mais recente, já permitiu resultados mais satisfatórios do que os alcançados pela aplicação do princípio da causalidade, que era a simples transposição do mundo físico (Santos, 1943). Além disso, a Psicologia Compreensiva estabelece como característica da totalidade anímica, a interconexão de sentidos do sujeito, ou seja, uma interconexão funcional dotada de sentidos compreensíveis e relacionados a valores buscados em seu próprio fim. Para citar um exemplo: um organismo tem sentido, na medida em que procura exercer as próprias funções para a autopreservação de sua vida, pois esta é, para si, algo valioso. Do mesmo modo, a vida anímica também é dotada de sentido no indivíduo, posto que as vivências têm significação em suas ações parciais e totais, nas funções de transformação da vida (Spranger, 1976).

É imprescindível comentarmos o conceito de "compreender” na perspectiva de Spranger, pois será utilizado para a aquisição do conhecimento na psicologia. Na visão generalista, se refere a apreender o sentido dos complexos abstratos, segundo um conhecimento objetivamente correto; com isso, entende-se o sentido do objeto no seu interior, dando-lhe significação. Ademais, deve haver a constituição de sentido daquilo que se deseja apreender, percebendo o que é sentido na abordagem compreensiva da análise e incorporado com valor significativo.

Do entrelaçamento da conexão de sentidos da vida individual depende a estrutura para a formação do indivíduo, e não só o sentido é voltado à autoconservação e ao mero prazer de viver. Como pode o sujeito vivenciar objetos considerados valiosos, sem que nada se relacione à autoconservação imediata? Expliquemos melhor: o prazer estético, por exemplo, pode ser experimentado pelo indivíduo como algo muito prazeroso e importante, embora não tenha, em suas manifestações, uma finalidade biológica vital (Spranger, 1976).

Tendo em vista o saber psicológico como uma forma de apreender a história do sujeito, é fundamental percorrermos a via social histórica, incluindo os conhecimentos e as práticas culturais como elementos essenciais à Psicologia - embora sejam anteriores e desenvolvidos de forma paralela, têm sua expressiva importância. Por isso, a cultura tenciona ajustar melhor a fundamentação sociocultural da Psicologia por meio da história. Isso possibi- lita a compreensão das relações entre processos psicológicos (objeto de estudo da Psicologia) e fenômenos culturais (expressões das diversas culturas) (Carvalho, 1997).

\section{Alguns aspectos sociais e psicológicos da juventude.}

Aspectos sociais e psicológicos da juventude são semelhantes à prosperidade de uma árvore, ou seja, no seu desenvolvimento natural são percebidas as etapas da lei que a governa e que a constitui como espécie, como exemplifica Spranger (1976). Se ela for impedida por falta de energia, luz e calor, muitas vezes ainda permanece viva, apesar de ter sofrido eventualidades que lhe causaram alguns danos. Do mesmo modo pode acontecer ao psiquismo humano, em que há uma lei primitiva que rege e organiza o crescimento, além de governar seu desenvolvimento. Assim, a tarefa da Psicologia Compreensiva está em conhecer tal psiquismo, antes mesmo de se ter o conhecimento das confusas forças interiores destruídas por obstáculos externos e agressivos à sua evolução (Spranger, 1976).

Spranger (1970) ressalta ainda que, na fase da juventude, o sujeito perpassa as mesmas façanhas que acontecem na fase da maturidade. É possível, porquanto, revermos conceitos e características que mostram como os jovens transformam os conflitos em energia para a vida e o amor, além de apreendermos como se encara a vida sob o olhar da juventude, com sua particular beleza e coragem.

O psicólogo está sempre preocupado em indicar a personalidade como uma totalidade em função de conhecimentos mais reservados das relações vinculadas entre si nos diversos fenômenos mentais. Para isso, adota a análise de caráter interpretativo-compreensivo na Psicologia, na História e nas Ciências Sociais, e conta com o esforço das ciências humanas que necessitam entender os processos da experiência de seres vivos mutáveis, que precisam ser interpretados para que se extraia deles o seu sentido.

Podemos dizer que a compreensão é o meio de captação interpretativo do sentido ou da conexão de significados. O método nas ciências humanas deve ser de entendimento, e não de explicação causal desenvolvida nas ciências naturais. Isso porque o primeiro se refere à forma de pensamento que apreende os eventos carregados de sentidos em relação a uma totalidade contextual (Spranger, 1970).

A compreensão, portanto, é um processo cognitivo, mas não inteiramente intelectivo, apenas; é também um processo apreciativo, interessante e repleto de sentimentos vivenciados por nós. Logo, a Psicologia Compreensiva é indicada como uma das melhores formas para lidar com a problemática do jovem, sendo capaz de restabelecer os fenômenos isolados na unidade do todo e interpretar seu significado vinculado com o todo. No entanto, a forma como o jovem vivencia suas experiências, de imediato, não tem bastante importância e é limitada, pois se torna 
algo difícil de ser entendido por ele - os aspectos mais relevantes são melhores percebidos quando já estão com uma visão mais ampliada, em que se superam as contingências da juventude.

Enfim, a totalidade pela qual há de entender o homem é bem mais ampla do que sua vivência passageira (Spranger, 1970). Por assim dizer, a vivência já aconteceu, e dela resta o aprendizado; podemos considerar a presença da "intuição humana", que na maioria das vezes nos adapta melhor à situação contingente pela compreensão do fato (Spranger, 1970). Na definição de Spranger (1970), a fase do desenvolvimento que mais precisa de entendimento é a idade da juventude, pois, à medida que alcançamos nossa compreensão, aumentamos a capacidade de superação dos desafios próprios dessa idade. E, observa que nessa época ocorre algo extraordinário, como uma autorreflexão mais intensa do ser em si mesmo, tendo como consequência a descoberta do indivíduo como um mundo em si mesmo, desligado de tudo que existe fora dele (Ferreira, 1984).

De acordo com Spranger (1970), apesar de as aflições e os sofrimentos dos jovens em seus conflitos intermitentes - em que as lembranças da infância e os anseios por alcançar a maturidade os atormentam com emoções expressivas e, às vezes, desconhecidas -, quase todos os sentimentos aflorados nessa fase são carregados de significações temporárias, mas com pouca eficácia para lembranças futuras. As emoções e angústias são logo esquecidas, o que pode revelar mecanismos inconscientes de não querer saber.

Em síntese, citaremos abaixo três pontos fundamentais da análise de Spranger, em relação ao fenômeno da juventude: o primeiro, a descoberta do $\mathrm{Eu}$; o segundo, o estabelecimento paulatino de um plano de vida, considerado importante, pois está o papel dele na projeção do Eu no futuro, manifestado a partir de fantasias; e o terceiro faz referência à inserção do jovem nas diferentes esferas da vida social, em que utiliza de um sistema de valores incorporados a ele no processo de individualização.

Como afirma Spranger (1970), a descoberta do Eu constitui a principal vivência para efetivar a individualização, e é nesse momento que surge o embate para escolher o "Eu-rei" entre os muitos "Eus" que se apresentam dentro de si mesmo. Ainda que esse processo aconteça secretamente, não tem nada no desenvolvimento humano que ocorra sob tão grande mistério como a construção do ideal da personalidade. Enquanto isso, o estabelecimento paulatino de um plano de vida é a tendência de dar continuidade a algo para além de si mesmo, uma projeção do "Eu" no futuro que, nesse momento, acontece com a autoafirmação, um movimento de integralização da vida pess oal com o ambiente ao seu entorno. E, por último, unido aos primeiros está o seu ingresso nas distintas esferas da vida, que é mediado pelas escolhas nomeadas num sistema de valores que coordena as atitudes e relações sociais do sujeito.
Podemos dizer que ele sonha com os papéis que poderá desempenhar no futuro, inclusive com sua escolha como algo exclusivo: trabalho, profissão... E, ninguém além dele, tem noção de como se vive tão freneticamente os bens e valores estéticos, lógicos e religiosos, ao mesmo tempo em que vive as noções do amor, da utilidade ou do poder (Ferreira, 1984).

Nesses termos, a juventude na cultura contemporânea é desenvolvida em múltiplos contextos sociais com características comuns, porém importantes, apontando para as diferenças impressas pela classe social. No contexto familiar, a maioria vive em dependência dos pais ou de seus familiares, mas, nesse período da vida, realiza a transição de um sistema de afeto, centralizado na família, para outro voltado aos pares. Além disso, tem de conviver com as angústias de se fazer participante da vida social (Spranger, 1970).

As mudanças culturais ou econômicas influenciam no desenvolvimento do indivíduo em formação, e os pais (ou quem exerce esse cuidado) têm a função ativa na sua constituição. Estes elegem determinadas possibilidades que lhes oferecem o meio cultural, mas transformam ou se opõem a outras. As características desses contextos são primordiais para o desenvolvimento saudável, visto que, no cenário familiar, a cultura, o saber e a ação se atrelam para a construção da base como experiência, que sustenta as vidas de seus membros (Silva, 2005).

No sentido econômico, tais indivíduos podem estar inseridos no sistema escolar ou num contexto de aprendizagem profissional, à procura de emprego ou praticando uma atividade econômica informal. Do ponto de vista do seu ethos ou da moral que rege os costumes da sociedade contemporânea, sentem-se inseridos numa cultura de coorte internacional. Tal aspecto se exprime por modas, hábitos, expressões linguísticas, estilos de vida, valores e preocupações específicas (Spranger, 1970). Na concepção de Spranger, o ser humano é constituído em suas extensões física, cognitiva, emocional, social, ética e estética. Isso condiciona um aprendizado que associe esses planos ao oferecer recursos para a constituição como pessoa e se inserir na realidade sociocultural (Spranger, 1976). Há o pressuposto de que aspectos parciais do sujeito e dos fenômenos a ele ligados fundamentam as leis gerais da sociedade. Conforme Morin (2005), esses fatores ordenam o mundo "perseguindo a desordem" e estabelecem identidades monolíticas.

Em síntese, Spranger (1976) mostra a existência de seis formas de valores arraigados na objetividade da ordem histórica e cultural, que dominam o indivíduo e suscitam um reordenamento dos outros em sua própria função. Tais valores são determinantes nos seis tipos de personalidades da cultura - o teórico, o econômico, o estético, o social, o político e o religioso - centrados respectivamente nos valores da verdade, da utilidade, da beleza, do amor, do poder e da religião. 
É importante destacarmos que a moral não constitui um tipo específico de valor, mas está inserida em todas as valorações. Assim, na análise do jovem, Spranger (1976) esquematizou os tipos humanos numa ordem ideal, sem, contudo, negar o livre arbítrio na escolha dos valores. Nessa linha de pensamento, o autor identifica oito tipos de personalidade na juventude: 1) o jovem preocupado com a saúde física, a vitalidade e o desejo de poder; 2) o tipo entusiástico-estético, com uma característica alegre e positiva diante da vida; 3) o pensador teorético, que pondera sobre o sentido da existência humana; 4) a pessoa ativa, interessada no progresso e no sucesso; 5) o tipo aventureiro que almeja a fama; 6) a pessoa altruísta e social, raridade entre eles, pois geralmente os jovens são egocêntricos; 7) o moralista entusiasta, defensor de seus princípios rígidos; e por fim, 8- o tipo religioso, encontrado com mais facilidade entre os jovens.

\section{A família no desenvolvimento do jovem - o primeiro ambiente socializador}

A importância da família no desenvolvimento do jovem - como o primeiro ambiente socializador, segundo Osório (1996) - é fundamental no desenvolvimento e na maturidade biopsicossocial. Existem algumas funções essenciais, destacadas em três categorias muito relacionadas entre si: biológica, psicológica e social.

Podemos dizer que da família vem à responsabilidade de garantir a sobrevivência da espécie humana, como função psicobiológica, em que oferece o cuidado necessário para o bebê humano se desenvolver de maneira adequada. No tocante às funções psicológicas, mencionamos três disposições básicas: 1) proporcionar afeto ao recém-nascido, elemento essencial que garante a sobrevivência emocional dele; 2) oferecer condições de suporte e continência para as angústias existenciais durante o processo de desenvolvimento, nos períodos das "crises vitais" como a adolescência; e 3) providenciar o aprendizado adequado para a inserção do sujeito no ambiente e a manutenção do desenvolvimento social e cognitivo, ainda segundo o pensamento de Osório (1996).

Já conforme Romanelli (1997), o ambiente familiar permite a expressão do amor e da amizade, em que estão inseridos relacionamentos íntimos e demonstração das emoções e dos sentimentos. Portanto, podemos dizer que no interior da família o indivíduo cultiva os primeiros relacionamentos interpessoais com pessoas significativas, produzindo os afetos que, por sua vez, funcionam como uma base afetiva importante quando ele alcança a maturidade. Essas trocas emocionais estabelecidas ao longo da vida são fundamentais para o desenvolvimento das pessoas, enquanto aquisição de condições físicas e mentais centrais para cada etapa da vida psíquica.

Osório (1996) também alude à função social familiar como o centro da comunicação cultural ou da transmis- são de sentido (Berger \& Luckmann, 2004) da sociedade aos seus membros, como também na preparação deles para o aprendizado da cidadania. Identificamos quando o processo de transmissão de sentido causa conflitos na formação da subjetividade, em que há desordens internas e a discrepância entre o "ser" e o "dever" se manifesta de tal modo a causar sofrimento ao indivíduo.

Nas palavras de Romanelli (1997), as normas e os valores introjetados no convívio familiar continuam durante todo o percurso da vida do sujeito, agindo como alicerce para a tomada de decisões e atitudes que se fazem necessárias no decorrer da fase adulta. Além disso, como diz Sarti (2004), a família permanece mesmo na etapa adulta, dá significados às relações sociais e atua na elaboração das experiências vividas. Concernente à família, ainda inferiu que a disposição das relações fundamentais é variável de acordo com a classe social das famílias. Com isso, a relação entre pais e filhos proporciona o vínculo mais intenso na conjuntura familiar, atrelando a representação da família de modo mais amplo e juntando a reprodução biológica à social, como argumenta Romanelli (1997).

A crise vivida na adolescência afeta direta ou indiretamente todos os familiares, permitindo repensar e sendo vista como uma fase do ciclo vital familiar que provoca intensas mudanças nas relações, sobretudo entre pais e filhos, como discorrem Pratta e Santos (2007). Isso porque, na visão de Cerveny e Berthoud (2001), pais e filhos estão em tempos distintos de transformações: jovens debatem sobre valores e regras familiares, preocupados com questões futuras, ao passo que seus pais já estão em um período de rever a problemática profissional, de reflexão e de mudança, até mesmo repensando o futuro.

Todavia, Romanelli (1997) arrazoa que o contexto familiar é também indispensável para a superação das crises pelas quais os jovens estão sujeitos durante todo o desenvolvimento natural da vida. É importante a reflexão sobre as modificações, a aceitação das diferenças e as mudanças pessoais dos membros que a constituem enquanto família. Naturalmente, conflitos e tensões obedecem a aspectos marcantes da vida familiar, dado que a expressão de sentimentos, aspirações e afetos é vivenciada com mais liberdade nesse âmbito. Para a manutenção da saúde familiar além da capacidade de superação das crises, são necessários qualidade das relações intrafamiliar e laços familiares adequados com a sociedade em que a família está alocada, conforme asseveram Pratta e Santos (2007).

Quanto à identidade e à crise generativa na juventude, alguns autores, a exemplo de Spranger (1970), acreditam que o eixo principal da problemática juvenil está na descoberta do "Eu" e no estabelecimento de um plano de vida, sendo que o sujeito escolherá um papel principal para atuação na maturidade. A juventude é a época em que são instituídas decisivamente as relações do "Eu" e do "Nós", em que também são superadas as relações com o infantil para formar uma nova trajetória através da vida. 
Geralmente, o indivíduo prova as transformações dessa fase pela ação comum de fatores internos e externos e pelas modificações mais profundas no âmbito da subjetividade, mas isso sugere crescimento, conforme a organização do complexo identitário. Para promover a evolução psíquica, tem-se como consequência o referencial dos valores que abarcam toda a trajetória histórica do sujeito; isso revela seu interesse por seguir determinada direção que lhe confere algum sentido, formando assim sua individualidade. Certamente, tais aspectos tornam cada indivíduo uma personalidade única, constituindo um mundo particular e incomparável - a sua identidade.

Agora, ao considerar os efeitos da atual globalização sobre a constituição da identidade e o advento da tecnologia na comunicação em rede, é relevante ressaltarmos os termos que definem o fenômeno "identidade" no contexto social atual. Admitimos que, para a formação de uma identidade, é necessária a existência de uma pessoa sujeita à ação dos processos elementares da individuação, integrados no espaço e no tempo (Menezes, 2010).

Nesse sentido, definimos como elemento central a pessoa humana, ou melhor, ela como indivíduo integrado, detentor de razão, consciência e ação. A essência desse sujeito é o seu mundo interno, tendo como o núcleo do "eu" a identidade da pessoa, mas "[...] essa é uma visão bem 'individualista' do sujeito e de sua identidade" (Hall, 2006, p. 11). De fato, demonstra-se que essa visão do "eu" interior do sujeito não pode ser considerada por si só uma entidade autônoma, nem autossuficiente; todavia, sofre influências das relações sociais, da cultura, dos valores e símbolos sociais - a identidade é desenvolvida na 'interação' entre o 'eu' e o meio social (Hall, 2006).

Como a identidade é um produto social decorrente da influência mútua entre o indivíduo e o contexto social, ela abrange dimensões como papéis (professor, médico, por exemplo) e relações sociais (parentesco, amizade etc.), além da identidade grupal (classe, geração, entre outros). Ainda, é constituída de elementos ou atributos procedentes da inter-relação social, considerando um conceito mutável (passível de transformação), dependendo da circunstância em que o interlocutor se encontra e com quem o narrador completa sua identidade (Menezes, 2010). Conforme o referido autor, o fenômeno da identidade social, isto é, o sujeito enquanto participante do grupo social, na medida em que as sociedades se tornam complexas, adquire uma configuração mais coletiva. Como consequência, a significação de sujeito se torna mais social: ele é visto como mais situado e "definido" no contexto estrutural e formador que sustenta a sociedade moderna.

Lembramos que a identidade é uma convenção social indispensável e ambivalente: do mesmo modo que liberta, explora. Ao mesmo tempo em que alimenta a ilusão de pertencimento, aponta a frustração do ser excluído; e busca alcançar o improvável: “[...] diferentes, mas os mesmos; separados, mas inseparáveis; independentes, mas unidos" (Bauman, 2005, p. 16). No diálogo com diversos autores sobre o tema "identidade no grupo social", é possível percebermos nitidamente que a contradição surgida na identificação da identidade origina a diferença e, por conseguinte, as questões constituintes da subjetividade. Ela tem como característica importante, a marca da diferença, isto é, para que exista determinada identidade, deve delimitar as diferenças que a distingue de outra identidade. Logo, elas são determinadas por meio de oposições binárias: ser A significa não ser B e vice-versa.

A identidade está sempre relacionada com a diferença e assinalada com a definição e o reconhecimento da diferença. Expondo: "[...] é na relação com o outro que me identifico como o não 'outro"' (Oliveira, 2006, p. 27). Nas inúmeras sociedades é óbvia a existência das diferenças que vêm atravessadas pelos valores culturais, fazendo com que as identidades possam ser vistas apenas nos sistemas de significação, constituindo elementos de uma cultura - são formadas pelos sistemas simbólicos. Em outras palavras, a identidade e a diferença não são elementos da natureza; antes, permeiam o social e são elementos fabricados nas relações sociais e culturais, algo documentado por Menezes (2010).

Vale considerar que a construção da identidade do sujeito deve estar ligada diretamente à sua cultura. Assim, no novo contexto cultural, o corpo toma lugar como um objeto de design, pois a personalidade necessita ser mostrada na própria pele, pelo físico. Afinal, vivemos em uma cultura do espetáculo, da aparência e da visibilidade em que é preciso aparecer para ser (Sibilia, 2008).

Diante disso surgem questões como: Será que as novas formas de subjetividade carregam consigo aspectos de uma falsidade ou a falta de autenticidade? Utilizam-se máscaras ou será que existe uma nova forma de subjetividade plástica e mutante? (Sibilia, 2008). Por meio da habilidade de metaforizar do sujeito que ele se torna apto a criar acordos e alianças, obtendo um espaço necessário para constituir a própria singularidade. Porém, quando ele, ao invés de introjetar, realiza o mecanismo de incorporação muito comum na contemporaneidade, exclui-se a habilidade de obter qualquer tipo de troca simbólica, em que assume uma identidade mortificante e desestruturante e se torna alienado (Sibilia, 2008).

Ainda pensando na sociedade de hoje, em que os valores estão cada vez menos estáveis, é possível questionarmos como o indivíduo assume uma identidade diante dessa instabilidade, e como esta sustentará sua própria subjetividade. Então, ele se encontra na contemporaneidade em pleno desamparo, buscando, a qualquer modo e custo, se inserir em um laço social seguro e estável. $\mathrm{Na}$ tentativa de não se sentir excluído, estabelece-se em relações grupais baseadas na alienação, pois se submete a normas impostas, ficando ausente a capacidade de livre arbítrio e reflexão, como analisam Herzog e Salztrager (2003).

Além disso, os jovens normalmente são portadores de diversos conflitos consigo e com a sociedade, numa fase do desenvolvimento em que há grande demanda de pul- 
são sexual, de busca pela autonomia e, ao mesmo tempo, necessidade de se sentirem seguros e acolhidos pelos adultos. Quando o comportamento antissocial surge da privação de cuidados, de afeto ou atenção por parte da sociedade e dos familiares, a delinquência é um pedido de socorro, uma forma radical de ter a atenção da sociedade e dos pais, frente à ausência de referencial na vida, como dito por Winnicott (1987).

Sob o viés psicológico, a amplitude e o volume dos resultados psíquicos, por exemplo, variam conforme o contexto social do indivíduo. Esse estágio do desenvolvimento humano é considerado a última e agitada etapa, que separa a criança do adulto que ela pretende ser (Mahoney\& Almeida, 2000). Neste período, complementa Spranger (1970), a vida se torna mais afetiva e intensa, o que toma certa importância, que surpreendem os outros. Isso mesmo tendo como destaque uma das características mais relevantes deste período: a ambivalência de atitudes e sentimentos; consequência dos aspectos afetivos e imaginativos, que causam desequilíbrio interior, como o desejo de oposição e conformismo, posse, renúncia e aventura.

No entanto, da ambivalência podem surgir as necessidades de conquista e os desejos de independência, sair da rotina, seguir novos ideais e participar de novos grupos de jovens que incorporem os mesmos valores e ideias. Daí a busca de satisfação das próprias necessidades com ações concretas, cujos resultados podem ser positivos ou negativos, de acordo com a regulamentação social e moral vigente no seu tempo, como apontam Mahoney e Almeida (2000).

\section{A crise de identidade, crise de sentido e hierarquia dos valores: o jovem em questão}

A crise de identidade é algo importante porque, conforme Spranger (1970) é uma fase de escolhas dos valores sociais e morais que o jovem necessita para sua relação com a sociedade. Segundo Mahoney e Almeida (2000), para que isso aconteça de forma mais adequada, indica-se que na relação com a educação não haja discriminação quanto à origem e à classe social ou étnica.

Para Mahoney e Almeida (2000), ao mesmo tempo em que o jovem quer a liberdade do adulto, ele necessita de orientações nas escolhas e realizações que favoreçam o crescimento pessoal. Assim, como descreve Spranger (1970), as relações de dependência e oposição ao outro desenvolvem os recursos necessários para o desenvolvimento da personalidade e os exercícios primordiais para a construção de sua autonomia. Essa oposição ao adulto é sustentada pelo jovem com os argumentos adquiridos na fase da puberdade e possibilita a imposição de exigências racionais.

No intercâmbio dessas discussões ou mais propriamente na crise de identidade, o jovem carece de atenção, escuta, valorização e respeito à sua individu- alidade, embora também necessite de sansões e parâmetros que estabeleçam as normas na elaboração de sua identidade social, assunto abordado em Mahoney e Almeida (2000).

Sobre a crise de identidade, de sentido e a hierarquia dos valores do jovem, Spranger (1976), em sua obra "Formas de Vida", nos permite ponderar sobre o indivíduo e sua tomada de posição no que refere aos valores, para poder inseri-lo no contexto de uma moral social e historicamente desdobrada, que permita a dialética dos conflitos nas decisões pessoais. Tem-se em vista os critérios científicos colocados por uma ordem hierárquica dos valores pessoais e concretos.

A comparação inicial dos gêneros ou classes valorativas é pertinente, pois a existência de uma ordem gradativa entre eles se torna questionável. Todo o valor econômico que seja considerado inferior ao valor social, a nosso ver, é algo feito por antecipação controversa para uma discussão. Entendemos, assim, que os critérios de graduação muitas vezes são estabelecidos apenas pela relação lógica dos valores, ou seja, por uma variação geral e apropriada para todos que enquadrassem em suas vivências. Dessa forma, mencionamos aqui, como vivência adequada dos valores, nada mais que o modo de viver subjetivamente, em conformidade à norma aguardada (Spranger, 1976).

Essas colocações de vivências gerais e adequadas condicionadas pelo espaço, tempo e matéria nos permitem idealizar, por exemplo, determinada situação em que, num certo momento de emergência, somos condicionados a prejudicar nossos amigos. Isso não indica que eles sejam menos "valiosos" para nós do que nosso próprio interesse (Spranger, 1976).

Outro ponto de vista diz respeito à recusa de comparação entre valores. Podemos dizer que as vivências: econômica e estética, isto é, a satisfação de uma necessidade e a admiração de algo encantador, pode ter considerações diferentes entre si. Quem poderia expressar, em valor monetário, quanto custa um amor para alguém? Ou quem ainda divulgaria, em unidade de amor, quanto custou um objeto comprado? Com isso percebemos que os valores estão unidos dentro do indivíduo, são importantes no seu conteúdo e determinantes para a existência, bem como para a formação da vida.

Sintetizamos, pois, que a incomparabilidade dos valores se deve às qualidades de cada valor que não permitem suas mensurações e nem podem ser publicadas com exatidão (Spranger, 1976). Os valores não se encontram como características rígidas nas representações psíquicas, mas estão inseridos, de maneira significativa, no interior da estrutura da pessoa e ligados à experiência vivenciada biograficamente - sua intensidade depende da vivência e do contexto em que está inserida.

O conteúdo de um valor não está determinado por apenas um tipo de valor; deve ser considerado o seu contexto e ser mais abrangente no sistema que o coordena, por exemplo: mesmo que o "amor" seja superior ao "po- 
der”, para a autoconservação do Estado, o poder é mais importante que o amor e o cuidado por uma vida em particular. Sendo assim, o conteúdo de um valor é observado em grau de relevância na sua contextualização e, por isso, ressaltamos que o nível de uma vivência valorativa está em função de seu conteúdo metafísico. Igualmente, quanto mais conteúdo metafísico tiver um conhecimento, tantas vezes mais elevado se colocará no contexto da vida (Spranger, 1976).

Podemos assegurar que a relação lógica dos valores representa um sistema objetivo em repouso, e a apreensão do nível de valor transcorre no campo da realidade, de tal forma que a ordem hierárquica implicada é conquistada apenas individualmente, a partir das intenções do sujeito em relação ao processo da vida, por meio de frequentes experiências de valor, vivências normativas, conflitos e lutas cotidianas. Essa ordem não é algo oferecido e já acabado, mas um produto finalizado, amadurecido depois de muito sacrifício e conquistado por meio das realizações pessoais. Devem-se considerar as simples constelações dos fatos e, até mesmo, os condicionamentos inteiramente subjetivos (Spranger, 1976).

Spranger (1976) aproveita, em suas discussões, fundamentos da ética, da cultura e da educação, exercendo enorme influência nos problemas éticos e culturais de seu tempo ao desafiar questões graves como educação para o trabalho, orientação pessoal e vocacional e delinquência juvenil. Contudo, essas discussões são proferidas inteiramente no âmbito individual, na qual o escalonamento dos valores segue os parâmetros da consciência. Considera ainda a hipótese de uma ordenação hierárquica das espécies de valores estabelecida para as configurações de uma vivência adequada em acordo à perspectiva de satisfação do sujeito social.

Temos percebido a migração dos valores morais tradicionais para alguns não tradicionais divulgados e conduzidos pela mídia por todo o sistema de informação. Essa variabilidade responde pelas diferentes mudanças de formas de vida que podemos encontrar ao longo da história e da formação de grupos sociais. No percurso de uma dimensão sócio-histórica se desconstroem categorias e valores ou eles são simplesmente formatados, em que se criam novas perspectivas de vida sempre em combinação com modelos das gerações e suas relações, pois estas são construídas à medida que transcorre a história condizente com sua época (Minerbo, 2000).

Com a constante perda e o esvaziamento dos valores humanitários, a sociedade pode transmitir, com certa incerteza, seus padrões éticos às novas gerações que até pouco tempo eram considerados elementos sociais imutáveis. Assim, nossos jovens se vêem em meio a um emaranhado de afirmações conflitantes, em que o bem se confunde com o mal e, para se afirmar no meio social, às vezes é necessário auxílio (geralmente da escola), para que possa ultrapassar o "nada" presente no percurso do desenvolvimento pessoal.
Ao analisarmos o trabalho de Trípoli (1998) percebemos que, devido ao desconhecimento por parte da sociedade sobre a hierarquia de valores estabelecida, os jovens têm tido sentimentos conflitantes em relação à importância dos valores morais e culturais. Assim, a autora afirma que estes são elementos funcionais do processo social que existem a cargo de quem os avaliam ou de grupos que os consideram como válidos e significativos, e variam de acordo com o contexto e a temporalidade, embora cada sujeito possa desenvolver o próprio sistema de valores, isto é, uma modificação dos valores institucionais colocados à disposição de cada um.

Sob o olhar científico de Hobsbawm (1995) citado por Trípoli (1998) existe uma sociedade que cada vez mais está abalada em suas crenças morais, em que foram arquivadas as noções claras de sociedade, classes sociais e instituições. Na eminência de defender uma nova ordem e estilo de vida, estava-se disposto a negar as formas de organizações já vivenciadas anteriormente, em vez de constituir uma proposta coerente com ela.

Nesse sentido há as vozes ouvidas na luta por uma demarcação histórica, na qual é apresentado como condição um ouvir mais apurado, focado nos anseios, bens e valores de uma juventude em processo de transformação na personalidade e nos valores já adquiridos. Quando estabelecemos uma relação entre gerações entendemos que, embora os conflitos sejam complexos, cheios de nuances e de forte identidade entre pais e filhos; eles vivem uma crise histórica. Nesse aprendizado de convivências cotidianas com o desmantelamento total de instituições, economias, expressões culturais, as gerações se distanciaram, o que constitui a "destruição do passado" (Trípoli, 1998).

Com a fragmentação do conhecimento e dos valores aliada ao distanciamento entre as gerações, os jovens têm vivido um tempo fictício, sem passado ou futuro. A "temporalidade líquida” leva o jovem a viver em um constante presente, sem relação com o passado histórico de seu tempo, ou seja, o pensamento está conectado no imediatismo, do aqui e agora, e nada mais importa (Trípoli, 1998).

Ainda nesse cenário, as representações sociais estão falseadas pela aparência do novo, da positividade em relação aos avanços desenfreados da tecnologia, mas outra vez nos defrontamos com as tragédias, a fome e a miséria que nos conectam a uma realidade crua e dura. No cerne disso está a instituição mais importante para o jovem: a escola - nesse cenário de construção e desconstrução da história se encontra o mesmo jovem esperançoso cheio de expectativa, mas desnorteado psiquicamente.

Com isso, os atores nos seus dramas pessoais são fragmentos da história e produtos da ação histórica dos homens. Eles são parte de nós e, pensando assim, participamos parcialmente do resgate da memória de valores culturais esquecidos e transformados ao longo do percurso histórico da sociedade. Notamos que, a sinceridade é mais valorizada do que a integridade, a autenticidade, mais que a honestidade, e nessa sequência de relação dos valores 
podemos inferir que, quando uma pessoa decide por algo sozinha, na verdade, isso não ocorre totalmente de maneira pessoal, dado que o indivíduo faz parte de uma época histórica, é um ser inserido na rede de relações sociais e imerso numa cultura da qual adquiriu regras, critérios, valores e juízos de valor, ou seja, se constituiu por uma cultura e portando é detentor de uma significação social (Trípoli, 1998).

Para Trípoli (1998), o espaço familiar é substituído por escola e ruas, e o jovem é jogado literalmente para a cena social, convivendo com os conflitos não mais mediados pelos pais e/ou cuidadores. A autora afirma que o problema de coerência existencial está entre o "dizer” e o "ser" na contradição entre adultos e jovens. A rebeldia e o desejo de independência destes da geração precursora fomentaram a intolerância e o individualismo.

O jovem brasileiro no seu contexto e os conflitos nas relações com a sociedade de adultos são regulamentados, de um lado ao outro, pelo direito estabelecido pelo Estado, tanto no que se refere às leis quanto a costumes e formas de conduta social. Também estamos cientes de que, na maioria das vezes, as regras externas trazem constrangimentos a ele que, num primeiro momento, percebe o mundo como algo de total liberdade de movimento, sem muitas normas para seguir; contudo, muito cedo entende que, sem as normas que regulam o exercício da vida social, fica difícil se constituir enquanto ser social.

\section{Considerações finais}

A partir da Psicologia Compreensiva de Eduard Spranger buscamos as impressões dos traços essenciais "forçados" na formação da identidade e do caráter do jovem. Este, por sua vez, é condicionado a seguir a regulamentação do processo evolutivo de sua sociedade, pois lhe encoraja a uma colaboração voluntária para a entrada dele na vida produtiva do país.

Reafirmamos com este estudo a necessidade de lançar novos olhares para concretizar uma política que tenha em vista o jovem no seu contexto, mesmo que isso não signifique ainda uma condição para configurar políticas mais adequadas que naturalizem e equalizem a condição juvenil no Brasil. É verdade que a criação de fóruns ou conselhos de juventude tanto no nível estadual quanto municipal, para a implantação de conselhos gestores de centros de juventude, tem se desenvolvido de forma a ser percebida. Mesmo sem existir clareza sobre qual o melhor caminho para as ações serem desenvolvidas com a juventude, compreendemos que a participação dos jovens na formulação, implantação, execução e avaliação de projetos políticos estão, pelo menos, na linha de horizonte das ações planejadas pelo governo.

A questão que lançamos se refere a colocar em dúvida a função que as políticas públicas exercem para assumir o papel socializador, possibilitando que os jovens criem entrelaçamentos da vida com a sociedade. Para isso, é necessário prosseguir para além das doutrinas de segurança pública e de assistência social no que diz respeito às políticas públicas voltadas para os jovens sem, contudo, negligenciar as dificuldades de ampliação dos dotes orçamentários para as políticas sociais - o maior desafio é inscrever as políticas de juventude em uma pauta ampliada de direitos públicos de caráter universalista. Isso os pressupõe como sujeitos autônomos e interlocutores ativos na formulação, execução e avaliação das políticas a eles destinadas.

A pesquisa fez com que percebêssemos a importância da Psicologia no estudo sobre o jovem e, principalmente, o seu ingresso no meio social. Nessa fase, as crises estão entrelaçadas aos vínculos pessoais e sociais, embora elas não estejam diretamente relacionadas a valores sociais. Pontuamos ainda que a crise de emancipação de si e do social, mesmo que carregue consigo o motivo por independência, tende a se deixar conduzir pelos valores e a se inscrever numa forma pré-estabelecida pela via cultural e social.

Ademais, este estudo nos proporcionou a percepção de especificidades dos jovens, como o motivo pelo qual são apreendidas as grandes mudanças e lutas sociais, isto é, de serem valorizados; e reconhecer o valor de si próprio e tornar esse valor individual aos demais. No entanto, não podemos nos esquecer do sentido dos valores consolidados neste período, por ocasião o da estética, da aparência perfeita, tão em voga nos dias de hoje. O jovem, ao querer impressionar ou produzir um interesse no outro, atua com o desejo do exibicionismo corporal, muitas vezes buscando atenção para si mesmo. Isso pode levar ao extremo que gera cuidado excessivo da aparência e grita solenemente às representações de seu mundo interno, como que dizendo: "Sou alguém, ocupo um lugar no espaço social, quero e necessito que me vejam, me admiram e me compreendam exatamente como sou".

Nesse entremeio, a estética no meio social jovem é hipervalorizada. Apesar de algumas inibições e timidez os jovens, na maioria, entram pelo caminho bem calculado do desejo íntimo de serem interessantes ou perfeitamente lindos para terem reconhecimento do grupo. Nas festas e baladas noturnas, eles encontram a oportunidade para se autoafirmarem, embora essa exposição possa representar o ressoar de inseguranças e falta de maturidade - quando encontram sua plenitude ou maturidade, por exemplo, há uma tendência de se distanciarem naturalmente dessa forma de lazer.

A mudança do espaço-tempo é sinalizada na passagem da faixa etária consolidada nos produtos de consumo que rotulam, etiquetam e criam a imagem dos jovens baseados na estética e no poder econômico. No lugar da busca pela identidade estão os ritos que promovem a perda da identidade, ou melhor, a alienação social e cultural do indivíduo enquanto está nas vias de ser um sujeito social. 
Nessa interação social, o mito do jovem, no lugar de reafirmação enquanto sujeito social aprofunda na alienação e o impossibilita de ser o agente para redesenhar os próprios caminhos. De certa maneira, ele está "proibido de ser", como afirma Trípoli (1998): hoje temos o "império do jovem" sobre o comportamento do adulto e o mundo, em que reinam a beleza física, o poder, a inteligência, a capacidade e o desejo de conquistar o mundo com seus atributos. Tais aspectos se unem às pressões de ordem política e socioeconômica que o fragilizaram no percurso da maturidade e da identificação de seu papel social.

Aqui reunimos os aspectos mais relevantes da pesquisa realizada, com a intenção de enriquecer a discussão sobre os desafios da presença da juventude com o entendimento da psicologia de Eduard Spranger (1970), para notarmos que o conhecimento e a concepção de mundo do jovem, são dois círculos que se cortam sem coincidirem.

Do ponto de vista psicológico são necessários repetição, elaboração, crítica intelectual e confrontação com a ciência do seu tempo para que assim haja entendimento da própria posição diante do mundo juvenil. Em se tratando do jovem, esses pensamentos decisivos se tornam mais complicados, levando em conta o pensamento "radical" que tende a abarcar os conflitos com reduzida quantidade de conceitos muito amplos, desconsiderando a existência de controvérsias.

Questionamos como estão esses jovens atualmente: o tempo pleno é o presente; os valores são vistos como critérios existenciais; a vida passa pela cabeça e, com a finalidade de encontrar a melhor qualidade de vida, é preciso atribuir valor a ela; para se alcançarmos a melhor vida, precisamos de critérios, com vistas a perceber qual vale mais; e assim podemos escolher o que tem maior significado no momento. É possível concluir, pois, que os conflitos são semelhantes aos jovens de diferentes gerações.

Chegamos à fronteira entre a reflexão científica e do senso comum (autoajuda, palestra motivacional e qualidade de vida) que está presente na vida operacional do indivíduo e provêm da premissa de que, "se agir de certo modo, vai dar bem na vida”. Já a ciência nos confirma: não é possível ter essa certeza, haja vista que o sujeito tem muitos valores agregados a si mesmo que não são coerentes entre si. Sem isso, as respostas são diferentes para o mesmo problema, em que há a capacidade de argumentação significativa, sempre de acordo com os critérios existenciais adotados para as escolhas situacionais.

As questões atuais que envolvem a juventude lançam um desafio que exige conceber a juventude em sua multiplicidade (juventudes) e requer a continuidade da ampliação das políticas públicas dirigidas aos jovens. Vários pensadores, vistos anteriormente, pregam que nossas ações no cuidado com o jovem devem proceder de uma atividade intelectiva (racional), isto é, ajustadas aos nossos critérios que também estão propensos à contradição em relação aos nossos desejos. Portanto, asseveramos que a vontade pressupõe a reflexão racional sobre a melhor maneira de vida do jovem.

\section{Referências bibliográficas}

Amorim, R. H. P. (2011, outubro). O jovem, o estatuto da juventude e a EC 65/2010. Âmbito Jurídico, 14(93), n. p. Recuperado dehttp://www.ambito-juridico.com.br/site/?n_link=revista_ artigos_leitura\&artigo_id $=10545$

Bauman, Z. (2005). Identidade: entrevista a Benedetto Vecchi (C. A. Carneiro, Trad.). Rio de Janeiro: Jorge Zahar.

Berger, P. L.,\& Luckmann, T. (2004). Modernidade, pluralismo e crise de sentido: a orientação do homem moderno (3. ed., E. Orth, Trad.). Petrópolis: Vozes.

IBGE (2000). Censo Demográfico, 2000. Brasil: Instituto Brasileiro de Geografia e Estatística.

Carvalho, J. M. de. (1997, dezembro). Delfim Santos e os temas culturais. Educação e Filosofia, 11(21/ 22), p. 39-55.

Cerveny, C. M. O. \& Berthoud, C. M. E. (2001). Visitando a família ao longo do ciclo vital. São Paulo: Casa do Psicólogo.

Ferreira, B. W. (1984). Adolescência teoria e pesquisa. 2. ed. Porto Alegre: Sulina.

Gomes, W. B., Holanda, A. F. \& Gauer, G. (2004). Psicologia humanista no Brasil. Museu Virtual da Psicologia no Brasil. Porto Alegre: Museu PSI. Recuperado de: <http://www.ufrgs.br/ museupsi/brasilpsio.htm>.

Hall, S. (2006). A identidade cultural na pós-modernidade. Rio de Janeiro: DP\&A.

Herzog, R., \& Salztrager, R. (2003). A formação da identidade na sociedade contemporânea. In T. Pinheiro (Org.), Psicanálise e as formas de subjetivação contemporâneas. Rio de Janeiro: Contra Capa Livraria.

IPEA. (2017). Mercado de trabalho: conjuntura e análise. Instituto de Pesquisa Econômica Aplicada: Ministério do Trabalho.

Lima, T. C. S., \& Mioto, R. C. T. (2007). Procedimentos metodológicos na construção do conhecimento científico: a pesquisa bibliográfica. Revista Katálysis, 10(Nr. Especial), 37-45.

Marconi, M. A., \& Lakatos, E.M. (2003). Fundamentos de metodologia científica. 5. ed. São Paulo: Atlas.

Menezes, T. D. de (Org.) (2010). A identidade social: uma análise teórica. Revista Prolíngua, 5, 16-27.

Minayo, M. C. de S. (1994). Pesquisa social: teoria método e criatividade. Petrópolis, RJ: Vozes.

Minerbo, M. (2000). Estratégias de investigação em psicanálise: desconstrução e reconstrução do conhecimento. São Paulo: Casa do Psicólogo.

Morin, E. (2005). Introdução ao pensamento complexo. Porto Alegre: Sulina.

Oliveira, M. F. (2006). A alteridade e a construção de identidades pedagógicas: (re)visando teorias dialógicas. In M. J. Coracini; M. Grigoletto, \& I. Magalhães. (Orgs.), Práticas identitárias: língua e discurso. São Carlos: Claraluz. 
Osório, L. C. (1996). Família hoje. Porto Alegre: Artes Médicas.

Pratta, E. M. M. \& Santos, M. D. (2007). Família e adolescência: a influência do contexto familiar no desenvolvimento psicológico de seus membros. Psicologia em estudo, 12(2), 247-256.

Romanelli, G. (1997). Famílias de classes populares: socialização e identidade masculina. Cadernos de Pesquisa NEP, 1-2, 25-34.

Rosa, M. V. F. P. C. \& Arnoldi, M. A. G. C. (2006). A entrevista na pesquisa qualitativa: mecanismos para a validação dos resultados. Belo Horizonte: Autêntica.

Santos, D. (1943). Psicologia e caracterologia. Boletim do Instituto de Orientação Profissional, 4, 31-52. Recuperado de: $<$ http://www.delfimsantos.org/textos/DSantos_psicologia _e_caracterologia_1943.pdf>.

Sarti, C. (2004). A família como ordem simbólica. Psicologia USP, 15(3), 11-28. http://dx.doi.org/10.1590/S010365642004000200002 .

Secretaria Nacional de Juventude (2014). Balanço da Gestão 2011-2014. Brasília. Recuperado de: <http://juventude. gov.br/articles/participatorio/0009/3632/Balanco_Gestao_ SNJ_2011-2014.pdf > .

Sibilia, P. (2008). O show do eu: a intimidade como espetáculo. Rio de Janeiro: Nova Fronteira.

Spranger, E. (1970). Psicologia da juventude (T. Newlands Neto, Trad.). Rio de Janeiro: Bloch.

Spranger, E. (1976). Formas de vida: psicologia entendida como ciência do espírito e ética da personalidade (G. A. de Almeida, Trad.). Rio de Janeiro: Zahar Editores.

Trípoli, S. G. (1998). A arte de viver do adolescente: a travessia entre a criança e o adulto. São Paulo: Arte \& Ciência.

Waiselfisz, J. (2014). Mapa da Violência 2014: os Jovens do Brasil. Brasília: Njobs Comunicação, 2014. 183 p. Recuperado de: <http://www.mapadaviolencia.org.br/pdf2014/Mapa2014_JovensBrasil.pdf> .

Winnicott, D. W. (1987). Privação e delinquência. São Paulo: Martins Fontes.

Siméia Rodrigues Campos - É Psicóloga, Graduada pela Universidade Federal de Uberlândia. E-mail: simeiarc@gmail.com

Tommy Akira Goto - É Professor Adjunto III, atuando na Pós-graduação e Graduação em Psicologia da Universidade Federal de Uberlândia. E-mail: tommy@ufu.br

Recebido em 02.03. 2017

Primeira Decisão Editorial em 12.06.2017

Aceito em 01.08.2017 